\title{
ЭКСПЕРИМЕНТАЛЬНЫЕ ПОДХОДЫ К ВЫЯВЛЕНИЮ СКЛОННОСТИ К БЛАГОТВОРИТЕЛЬНОСТИ
}

\author{
Э.С. Бабичева, Т.Л. Майборода, А.А. Кравченко
}

Рассматриваются экспериментальные способы выявления склонности к благотворительности и предпочтений групп реципиентов благотворительной помощи. Путем сопоставления результатов трех экономических экспериментов анализируется влияние особенностей экспериментального дизайна на определение предпочтений опрашиваемых, в частности, при использовании гипотетических сумм пожертвований и реальных денег участников. В ходе экспериментов выявлено влияние информирования потенциальных доноров о предстоящем сборе средств как на сумму пожертвований, так и на количество отказов от участия. Исследуется взаимосвязь личностных характеристик респондента и готовности участвовать в анонимной благотворительности. Обнаружены корреляции между склонностью к анонимной благотворительности и характеристиками экстравертности, открытости новому опыту. Даются практические предложения по организации поведенческих интервенций при организации благотворительных мероприятий и предлагаются возможные дальнейшие направления экспериментальных исследований благотворительной деятельности.

Ключевые слова: экспериментальная экономика, поведенческая экономика, благотворительность, дизайн экспериментов.

JEL-классификация: B41, C81, C90, C91, D03, D64.

DOI: $10.46782 / 1818-4510-2020-3-74-86$

Материал поступил 5.05.2020 2.

Проблема благосостояния всегда была предметом социальных и философских размышлений. Ведущие мыслители-экономисты либерального направления (А. Смит, Т. Мальтус, Д. Рикардо) считали, что снижение благосостояния и рост бедности неизбежное следствие превращения традиционного общества в индустриальное. Концепции определения и инструменты измерения благосостояния постоянно модифицируются под влиянием экономических, социальных, политических и институциональных факторов.

Шотландский экономист А. Дитон в своих работах придерживается мнения, что благосостояние можно определить «непривычными» методами, одним из которых является выявление склонности населения страны к благотворительности. В странах, где домохозяйства жертвуют время и день- ги, люди способны удовлетворять собственные потребности и делиться. Это означает, что мы можем исключить их из категории людей, проживающих за чертой бедности или «продовольственной» чертой бедности, несмотря на формальные критерии учета уровня бедности (Deaton, 2013).

Однако это предположение о положительной связи между уровнем благотворительности и благосостоянием стран, измеренном в привычных показателях (таких как ВВП на душу населения), не находит прямого подтверждения. Если посмотреть на данные ежегодного международного опроса CAF World Giving Index ${ }^{1}$, охватывающего 146 стран, то в рейтинге стран по всем трем показателям на первых местах оказываются как развитые

${ }^{1}$ von Neumann J. 1945. A model of general equilibrium. Review of Economic Studies. Vol. 13. No 1. PP. 1-9.

* Бабичева Элина Сергеевна (elinaice@mail.ru), Белорусский государственный экономический университет (г. Минск, Беларусь);

Майборода Татьяна Леонидовна (mtv_1@tut.by), кандидат экономических наук, Белорусский государственный экономический университет (г. Минск, Беларусь);

Кравченко Александр Александрович (wildsent@gmail.com), кандидат экономических наук, Белорусский государственный экономический университет (г. Минск, Беларусь). 
страны (например, Австралия, США, Ирландия), так и развивающиеся страны (Индонезия, Кения, Камбоджа). Очевидно, что религиозные и культурные традиции, сложившиеся социальные практики, этнические конфликты оказывают сильное влияние на склонность к благотворительности. В целом, если сравнивать результаты десятилетних исследований, то в развитых странах люди гораздо чаще занимаются волонтерством и больше людей жертвует деньги, тогда как в развивающихся странах охотнее помогут незнакомцу другим способом.

Страны Восточной Европы занимают места в нижней трети международного рейтинга склонности к благотворительности. Согласно данным 2018 г., Беларусь занимает 121 место: $31 \%$ респондентов оказывают разную помощь незнакомцам, 21 - жертвуют деньги и $19 \%$ - занимаются волонтерством. Таким образом, представляется актуальным исследовать, какие факторы влияют на склонность к благотворительности в Республике Беларусь, а также какие группы субъектов чаще являются получателями благотворительной помощи. Выявление предпочтений часто осуществляется опросными методами или в ходе эксперимента. В связи с этим представляет интеpec то, как влияет дизайн эксперимента (опроса) на результаты ответов реципиентов.

В статье рассмотрены результаты трех экспериментов, содержащих схожие опросные листы, связанные с благотворительностью. При этом в каждом из экспериментов ставились отличающиеся цели, собиралась различная информация об участниках, менялись социально-экономический статус респондентов и некоторые ключевые элементы дизайна экспериментов, что затрудняет полноценное сопоставление результатов. Несмотря на это, с нашей точки зрения, полученные результаты позволяют выделить важные закономерности, связанные как непосредственно со склонностью к благотворительности, так и с методологией проведения схожих исследований.

\section{Первый эксперимент по выявлению склонности к благотворительности}

Для проведения первого эксперимента был выбран один из офисов международной аудиторской и консалтинговой компании г. Минска. В выборку вошли люди разного пола, возраста, с разным уровнем дохода и образования. Время проведения - начало месяца, когда выплачивается заработная плата работникам, что дает возможность исключить вероятность того, что человек не жертвует только из-за бюджетных ограничений ${ }^{2}$.

На первом этапе случайным образом были определены три группы тестируемых численностью 15 чел. каждая. Сначала проводилась индивидуальная беседа с участниками первой (контрольной) группы с просьбой пожертвовать человеку на лечение, причем не упоминались ни пол, ни возраст больного ${ }^{3}$. Экспериментатор представлялся как волонтер благотворительного фонда. 11 человек из 15 были готовы пожертвовать деньги, при этом средняя сумма пожертвования составила 10,45 BYN, a медианное значение - 5 BYN.

Второй и третьей группе были отправлены электронные письма с указанием времени, в которое придет волонтер. В этом случае предполагалось, что если человек склонен к благотворительности, то количество, готовое пожертвовать, должно увеличиться по сравнению с контрольной группой, так как они заранее были оповещены о проводимом мероприятии. Разница между второй и третьей группами состояла в том, что тестируемые третьей группы могли отказаться от визита, установив статус «не беспокоить» при ответе на письмо. В этом случае проверялась склонность людей к благотворительности при возможности выбора ${ }^{4}$. Результаты обследования трех групп представлены на рис. 1.

${ }^{2}$ Следует отметить, что выбранный период времени мог завышать склонность к благотворительности. Например, эксперименты в Кении показали, что планирование и осуществление расходов меняются в зависимости от того, как давно получена выплата (Duflo, Kremer, Robinson, 2011). Частично это объясняется проблемами с гиперболическим дисконтированием и самоконтролем.

${ }^{3}$ Решение об отсутствии какой-либо конкретики было принято с целью исключить возможное влияние гендерной и возрастной дискриминации на принятие решения испытуемыми о благотворительной деятельности. При этом исключить вероятность «недоверия» к экспериментатору благодаря тому, что он являлся сотрудником того же офиса, в котором был проведен эксперимент.

4 Вдохновением для дизайна этого этапа эксперимента послужило исследование (Della Vigna, List, Malmendier, 2012), где задачей являлось выявить разницу между мотивами пожертвований. Если главный мотив - альтруизм («теплое свечение»), то должно наблюдаться увеличение пожертвований после предупреждения. Если мотивом выступает социальное давление, то количество жертвующих 


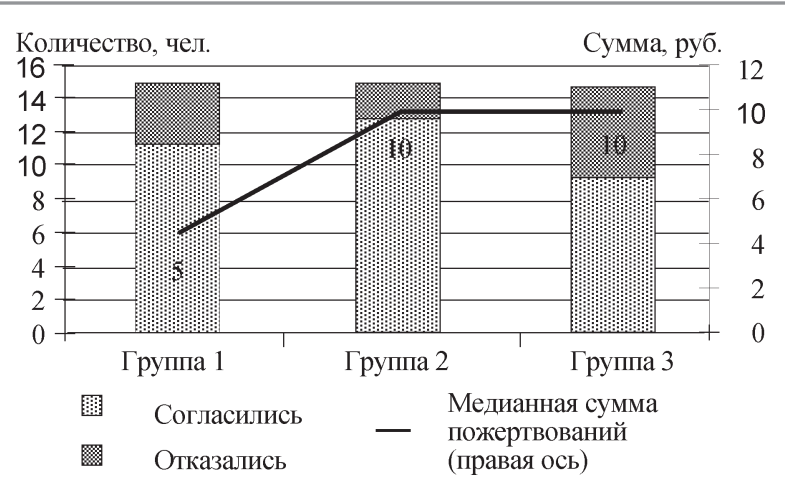

Рис. 1. Результаты обследования всей выборки из трех групп: количество людей, жертвующих деньги, и суммы пожертвований, BYN

Источник. Авторская разработка.

По результатам этого этапа нельзя однозначно сказать о мотивах: общий объем пожертвований возрос, как и количество жертвователей во второй группе, которая была предупреждена заранее. Возможно, люди осознанно подошли к процессу благотворительности, преобладал мотив «теплого свечения». С другой стороны, количество отказов в третьей группе увеличилось по сравнению с контрольной группой, что, вероятно, связано с отсутствием социального давления. Можно сделать вывод, что при неличном контакте человек в большей мере готов отказаться от пожертвований, чем при прямом контакте.

Полученные средние и медианные значения могут свидетельствовать о том, что выборки были схожими по уровню дохода участников, следовательно можно исключить вероятность того, что в какой-то из групп наблюдалось больше отказов из-за недостатка денежных средств.

На втором этапе вводилась исключенная ранее переменная - гендерная и возрастная дискриминация, чтобы выявить, каким категориям реципиентов люди склонны жертвовать деньги в большей степени. Всем трем группам людей, пожертвовавшим деньги на первом и втором этапах эксперимента, были розданы анкеты с предло-

сократится. В результате исследования более 7 тыс. домашних хозяйств в Чикаго, США было выявлено, что основным мотивом пожертвований является социальное давление: предупреждения о времени визита снижают на 1025\% долю домохозяйств, открывших дверь волонтерам; предупреждения с опцией отказа от визита сократили на $30 \%$ эту же долю. В основном это характерно для небольших пожертвований (менее 10 долл. США). жением сделать выбор между разными категориями людей и пожертвовать фиксированную гипотетическую сумму денег. Были включены следующие категории: «дедушка», «бабушка», «мальчик», «девочка», «животное», которые представлены картинками 5 . Чтобы участники осознанно делали свой выбор, поставлено следующее условие: по итогам анкетирования случайным образом будет выбрана одна анкета, где будет выявлен «приоритетный» субъект пожертвования, и именно данной категории будут пожертвованы все собранные деньги. Результаты анкетирования представлены на рис. 2.

Отдельно изучены варианты с возможностью оставить деньги себе. В данном случае учитывались все анкеты, в том числе и людей, не пожертвовавших деньги на первых этапах эксперимента. Обнаружено следующее.

1. Количество людей, выбравших вариант «я», превышает количество людей, на самом деле пожертвовавших в рамках эксперимента. Это можно объяснить тем, что гипотетическая сумма пожертвования достаточно высока (100 долл.), особенно если сравнить ее с реальными суммами пожерт-
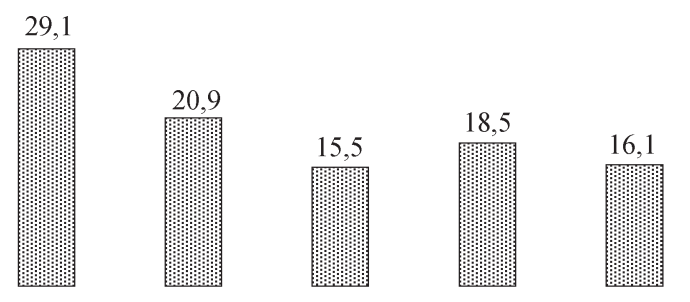

Девочка Мальчик Дедушка Бабушка Животное

Рис. 2. Распределение пожертвований по категориям, \% ${ }^{6}$

Источник. Авторская разработка.

${ }^{5}$ Подобные анкетирования по выявлению склонности к благотворительности и ее факторов проводит на своем сайте Массачусетский технологический университет. Респонденту предоставляется около десятка выборов между двумя вариантами пожертвований, где могут меняться не только категории реципиентов, но и их количество, сумма денег, причина сбора пожертвований, регион проживания. URL: https://mygoodness.mit.edu/quiz. Все это позволяет собрать большой массив данных, однако в целях простоты в рамках данного эксперимента был оставлен только выбор между разными категориями людей.

${ }^{6}$ Было проведено аналогичное исследование среди студентов Академии фигурного катания г. Минска, где «рейтинг» категорий оказался идентичным с результатами первичного эксперимента: на первом месте девочка, потом мальчик, бабушка, животное и дедушка соответственно. 
вований данной выборки респондентов. Кроме того, следует учитывать возможность получения субъектом опроса реальных денег в результате случайного выбора анкеты экспериментатором.

2. Между вариантами «я» и «мальчик» чаще выбирали вариант «я» по сравнению с другими парами. Это можно объяснить эффектом фрейминга, когда порядок появления опций выбора влияет на ответы респондентов. В данном случае выбор того, оставить ли деньги себе или отдать категории «мальчик», появляется в анкете первым. Скорее всего, опрашиваемые решали оставить деньги себе вне зависимости от того, какой бы был второй вариант. Когда они во второй и третий раз сталкивались с этим выбором, предпочтение отдавалось деньгам на благотворительность. Возможно, респонденты воспринимали процедуру выбора как «накопленную историю выборов», то есть они уже оставили часть денег себе, теперь «оставшиеся» деньги можно пожертвовать другим.

На третьем этапе анкетируемые, которые на первых этапах пожертвовали деньги, получили материал, в котором необходимо было ответить на 5 вопросов школьной программы ${ }^{7}$. Каждый последующий вопрос сложнее предыдущего. Максимальная сумма, которую можно было «заработать» за счет правильных ответов, равнялась сумме, которую пожертвовали на первом этапе эксперимента (50 BYN). Пропорционально тому, на сколько вопросов правильно ответил человек, ему выдавался виртуальный заработок. Затем анонимно, исходя из полученного заработка, каждому было предложено написать сумму (цифру), которую он готов отдать на пожертвование.

Здесь проверялось предположение о том, что люди склонны пожертвовать большую сумму денег, если деньги достались «легким» путем ${ }^{8}$. Полученные результаты сравнивались

7 Задания взяты из ЕГЭ по математике базового уровня. Об этом было объявлено сотрудникам международной компании заранее, чтобы задействовать стимул социального давления и чтобы им было стыдно не решить задачи школьной программы.

8 Готовность расстаться с «легкими» деньгами обусловлена тем, что человек перед принятием решений сопоставляет «стоимость» затраченных усилий на их получение с ценой и ценностью товара. Ведь «легкие» деньги не требуют много усилий, они легко могут быть потрачены, в частности на благотворительность. с исходными пожертвованиями как процентное отношение пожертвованных денег к сумме, имеющейся у них на руках (средняя дневная заработная плата - в первом случае, «заработок» от решения задач - во втором). Предположение было подтверждено. Так, люди в среднем жертвовали $19,3 \%$ от своей дневной заработной платы и 54\% «заработка» от решения задач. Однако к этим результатам следует относиться осторожно, ведь для расчета была взята средняя заработная плата по офису, которая является относительно высокой, при этом есть резкие различия в заработных уровнях, исходя из грейда работников.

Таким образом, в ходе этого многоступенчатого эксперимента было выявлено, что при неличном контакте человек с большей вероятностью откажется от благотворительности, чем при прямом контакте. «Рейтинг» категорий, которые готовы жертвовать деньги, выглядит следующим образом: девочка, мальчик, бабушка, животное и дедушка. Было подтверждено предположение, что люди склонны пожертвовать большую сумму денег, если деньги достаются «легким» путем.

В ходе этого эксперимента выявлены потенциальные проблемные вопросы, которые нуждались в решении в ходе последующих экспериментов.

Первой такой проблемой, с нашей точки зрения, является использование гипотетических денег (несмотря на внешнюю мотивацию через наличие вероятности повлиять на окончательное распределение денег, собранных группой тестируемых) при выявлении приоритетных категорий получателей пожертвований на втором этапе эксперимента. Такой дизайн эксперимента может не отражать реальные предпочтения отвечающего.

Предположим, выбор предпочтений относительно распределения благотворительности приносит индивиду пользу (TU), которая может быть представлена суммой полезностей от эффекта «теплого свечения», саморепрезентации себя для социума, самоидентификации, увеличения собственного дохода (если человек может оказаться реципиентом денежных поступлений). При этом любой выбор сопряжен с затратами как временных, так и когнитивных ресур- 
сов субъекта (ТС). Индивид будет выбирать такой набор своих предпочтений (n), который максимизирует разницу между полезностью данного выбора и издержками на его определение:

$$
\mathrm{f}(\mathrm{n})=\mathrm{TU}(\mathrm{n})-\mathrm{TC}(\mathrm{n}) \rightarrow \max ,
$$

где TU - функция общей полезности от принятого набора предпочтений;

$\mathrm{n}$ - вектор набора предпочтений индивида, где $\mathrm{n} \in \mathrm{N}, \mathrm{N}$ - совокупность всех возможных выборов;

ТC - функция общих издержек определения данного набора предпочтений.

Логично предположить, что существует такой набор $\check{n} \in \mathrm{N}$, который наиболее полно соответствует реальным предпочтениям индивида, при этом $\mathrm{TU}(\check{\mathrm{n}})=\max$. Однако выбор данного набора не обязательно будет приводить к максимизации функции $\mathrm{f}(\check{n})$, представленной в формуле (1), так как издержки со стороны индивида на его определение могут оказаться слишком высокими.

Таким образом, выбираемый набор $\mathrm{n}=\check{\mathrm{n}}$ только в случае, если $\mathrm{f}(\check{\mathrm{n}})=\max$.

Целесообразно также предположить, что издержки поиска набора, соответствующего реальным предпочтениям, будут выше, чем для случайного набора, т. е. $\mathrm{TC}(\check{\mathrm{n}})>\mathrm{TC}(\mathrm{r})$, где $\mathrm{r} \neq \check{\mathrm{n}}$ и $\mathrm{r} \in \mathrm{N}$.

Если опрос проводится сугубо умозрительно и анонимно, а следовательно, его результаты не приведут к перераспределению денежных средств и материальных благ в пользу представителя какой-либо группы, не будут вызывать у индивида эффекта «теплого свечения», а также не будут нести в себе ценности самопрезента-

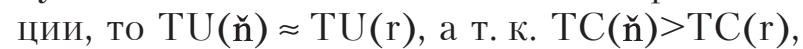
то $\mathrm{f}(\check{\mathrm{n}})<\mathrm{f}(\mathrm{r})$, вследствие чего индивид может отвечать, не согласуясь со своими реальными представлениями ${ }^{9}$.

В связи с возможностью возникновения данной проблемы в ходе проведения экономических экспериментов общим стандартом стало использование платы за участие (слабый стимул) и хотя бы одного

9 Можно предположить, что если индивид не отвечает согласно своим реальным предпочтениям, но при этом прошел опрос до конца, то TU(r) $>$ TC(r) для всех $\mathrm{r} \in \mathrm{N}$. выборочного платежа-вознаграждения в результате эксперимента (усиленный стимул). Так, Дж. Хоровитц считает, что использование небольших, но реальных денежных сумм в начале эксперимента хорошо помогает настроить участников на решение дальнейших задач (Horowitz, 2006). Однако в другой серии экспериментов не было выявлено разницы в реакциях на виртуальные и реальные деньги, даже в степени дисконтирования отложенных наград (Locey, Jones, Rachlin, 2011). Таким образом, существование разницы в реакции тестируемых на гипотетические и реальные денежные вознаграждения все еще остается дискуссионным вопросом. Тем не менее, пока существуют теоретические предпосылки для ее наличия, этим обстоятельством пренебрегать нельзя.

Второй проблемой эксперимента могла оказаться сумма, которую требовалось пожертвовать, т. к. ее величина была слишком высока по сравнению с выявленными средним и медианным значениями пожертвований на первом этапе эксперимента.

В эксперименте также был задан контекст людей и животных, нуждающихся в лечении. Однако благотворительные организации часто собирают деньги и с другими целями. Влияет ли это на выбор участников?

Нельзя исключать и элемент сощиального давления, т. к. волонтер собирал деньги в хорошо знакомом коллективе. Снизится ли объем пожертвований при другом дизайне эксперимента?

\section{Второй эксперимент по выявлению склонности к благотворительности}

Целью второго эксперимента было выявление наличия устойчивости предпочтений групп реципиентов благотворительности, обнаруженных ранее в ходе опроса двух категорий респондентов (работников фирмы и студентов Академии фигурного катания г. Минска) первого эксперимента. Для этого был сформирован аналогичный опросный лист, такой как на втором этапе первого эксперимента, за исключением формулировки вопроса. Респондентов просили определить, кому они предпочли бы передать 5 BYN в качестве благотворительности из фонда цен- 
тра «МеMicroMacro» ${ }^{10}$. Аналогично участники были проинформированы, что случайным образом будет выбрана анкета, по результатам которой определится группа реципиентов благотворительности (та, которая выбиралась чаще других).

В ходе эксперимента опрошено 60 студентов 1 курса Белорусского государственного университета информатики и радиоэлектроники (43 девушки и 17 юношей), средний возраст опрашиваемых составил 17,5 лет. Опрос проводился онлайн.

Проверяемое предположение: структура выбора получателей благотворительности будет близка к наблюдаемой в первом эксперименте, несмотря на изменение суммы пожертвований и источника денег (в первом эксперименте использовались деньги коллектива и гипотетические деньги).

Так как обе группы опрашиваемых в ходе первого эксперимента обладали различными социокультурными характеристиками и при этом структуры их выборов совпадали, можно предположить, что такая структура будет являться устойчивой и для других групп респондентов.

По результатам опроса, предпочтения реципиентов благотворительности распределились, в порядке убывания, следующим образом: «животным», «бабушке», «дедушке» или «девочке» ${ }^{11}$, «мальчику» (рис. 3). Полученные ответы существенно отличаются от результатов первого эксперимента. Таким образом, предположение об устойчивости предпочтений было отвергнуто. Существенное воздействие могло оказать изменение группы респондентов (в первом эксперименте средний возраст отвечающих был выше) или условий проведения эксперимента.

При этом, мы считаем, что использование реальных денег и соответствие суммы распределения медианной сумме благотворительности, выявленной в первом эксперименте, с большей вероятностью отражают реальные предпочтения отвечающих. Это можно раскрыть через следующую цепочку умозаключений.

${ }^{10}$ Сумма пожертвования была выбрана на основе результатов прошлого эксперимента - контрольная группа осуществила медианную сумму пожертвований в размере 5 BYN.

11 Категории «дедушка» и «девочка» набрали одинаковое количество ответов.

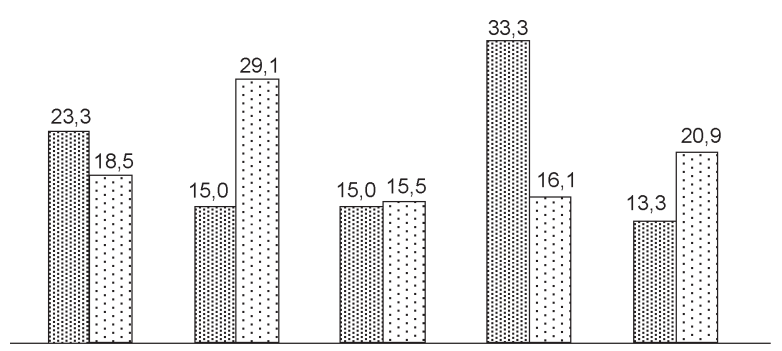

Бабушка Девочка Дедушка Животное Мальчик 疄 Опрос студентов :-: Опрос на фирме

Рис. 3. Распределение пожертвований по категориям (результаты перввого и вंторого эксперимента), \%

Источник. Авторская разработка.

В том случае, когда результаты выбора предполагают фактическое распределение денежных средств и материальных благ (М), не принадлежащих индивиду, произойдет увеличение полезности принимаемого индивидуумом решения $\mathrm{TU}(\check{\mathrm{n}}, \mathrm{M})>\mathrm{TU}(\mathrm{r}, \mathrm{M})$, по сравнению с ситуацией гипотетического опроса. Поскольку же увеличится полезность всей совокупности выборов, то $\mathrm{f}(\check{\mathrm{n}}, \mathrm{M})$ может все еще оказаться меньше $\mathrm{f}(\mathrm{r}, \mathrm{M})$. При этом для человека, проходящего тест случайным образом, будет также соблюдаться неравенство $\mathrm{TU}(\mathrm{r}, \mathrm{M}) \geq \mathrm{TC}(\mathrm{r})^{12}$ для всех $\mathrm{r} \in \mathrm{N}$. По мере роста М общая полезность от выбора TU(̌n, M) будет расти быстрее TU(r, M), или предельная полезность MU(г̌, M) будет больше MU(r, M). Таким образом, после достижения определенного уровня $\mathrm{M}=\mathrm{M}_{\mathrm{E}}$, при котором $\mathrm{f}\left(\check{\mathrm{n}}, \mathrm{M}_{\mathrm{E}}\right)=\mathrm{f}\left(\mathrm{r}, \mathrm{M}_{\mathrm{E}}\right)$, дальнейшее увеличение распределяемой суммы будет приводить к тому, что индивид будет стремиться осуществить выбор, соответствующий его реальным предпочтениям. Таким образом, результаты опроса, связанного с фактической передачей материальных благ другого лица при достаточном их объеме, в отличие от умозрительного опроса, будут с большей вероятностью иллюстрировать реальные предпочтения респондента.

Если же респондент принимает решение о распределении собственных денежных средств (Р), то это приведет к увеличению не только полезности выбора, как это было с чужими деньгами, но и издержек любого выбора. При этом для отвечающего уже может возникнуть ситуация, при которой

12 Распределение чужих денежных средств не изменяет прямые издержки индивида на осуществление выбора. 
$\mathrm{TU}(\mathrm{r}, \mathrm{P}) \geq \mathrm{TC}(\mathrm{r}, \mathrm{P})$ не будет верно для всех $\mathrm{r} \in \mathrm{N}$, а значит, отвечающий будет склонен стараться избежать таких выборов, которые делают функцию $\mathrm{f}(\mathrm{r}, \mathrm{P})$ отрицательной. Однако такое поведение потребует от него временных и когнитивных усилий, сопоставимых с поиском набора, соответствующего ре-

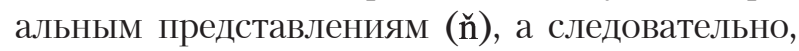
и отражение именно данного набора становится вероятнее. При этом, исходя из теории перспектив, по мере роста Р ТС(Р) будет расти большими темпами, нежели TU(P) для всех наборов выбора. Это значит, что по мере увеличения суммы собственных денег, относительно которой респондент принимает решение, все больше наборов будут соответствовать неравенству TU(r, P) < TC(r, P), а следовательно, будут сокращаться и вероятность случайных ответов.

Таким образом, структура ответов относительно предпочтений групп реципиентов благотворительности может отличаться в зависимости от того, принимает ли индивид решение относительно распределения своих или чужих денег. Это предположение легло в основу проведения третьего эксперимента.

\section{Третий эксперимент по выявлению склонности к благотворительности}

Перед авторами встала задача провести эксперимент с реальными деньгами среди студентов этичным образом ${ }^{13}$. Ход эксперимента выглядел следующим образом.

1. Группа добровольцев взяла с собой 5 ВҮN $^{14}$ одной купюрой и мобильное устройство с доступом в интернет. Заранее оговаривалось, что участие в благотворительности не является обязательным.

2. Участникам выдавались 2 конверта с обозначениями «A» и «1», инструкции со ссылкой на предварительный тест на понимание условий, основной тест и бумажный тест на выявление личностных характеристик («Большая пятерка» ${ }^{15}$ ).

${ }^{13}$ Не имея возможности платить участникам (что еще дополнительно искажало бы ход эксперимента), необходимо было найти такое решение, которое бы не приводило к злоупотреблению административным ресурсом преподавателей.

14 Время проведения эксперимента было выбрано таким образом, чтобы прошло не более одной недели со времени получения стипендии студентами.

15 Диспозициональная модель личности человека, отражающая восприятие людей друг другом, построенная на самоотчетах. Было предпринято несколько попыток русско-
3. Результаты каждого участника были обработаны с целью выявления приоритетной категории для пожертвования. Участнику выдавалась картинка с победившей категорией. После этого он клал деньги в один из двух конвертов и переходил к папкам для пожертвований. Таким образом, только сам студент знал, в каком конверте находятся его деньги.

4. Организатор просил еще раз проверить, какой конверт он хочет отдать, и показывал, в какую папку он может положить свой конверт «1» или «А». Второй конверт он оставляет себе как вознаграждение ${ }^{16}$. Собранные деньги по каждой категории были пожертвованы от имени студентов БГЭУ соответствующим благотворительным кампаниям ${ }^{17}$.

Были сформулированы три основных предположения.

Первое: результаты выбора категории получателя благотворительности будут отличаться в зависимости от условий проведения опроса (распределялись ли чужие деньги или собственные деньги респондентов).

Как отмечалось ранее, распределение собственных денег в качестве благотворительной помощи увеличит издержки выбора группы для благотворительности, тем самым может сократиться вероятность случайного ответа. Возможна также ситуация, при которой респондент отказывается распределять свои деньги в пользу других людей, выбирая себя в качестве реципиента, как это предусмотрено в эксперименте. Тем самым он снижает издержки для всех своих последующих выборов, и ситуация для него становится аналогичной опросу с гипотетическими деньгами.

язычной адаптации опросника. Здесь использован короткий 10-вопросный опросник, соответствующий критериям валидности стандартных опросников (Егорова, Паршикова, 2016).

16 Поскольку на конвертах было сразу написано, что они подарочные, то их можно рассматривать как стимул к повышению склонности к благотворительности. Дополнительное искажение могло возникнуть из-за того, что происходил «самоотбор» участников эксперимента, они заранее знали и были готовы жертвовать в большей степени, чем те, кто не пришел.

17 Студентам заранее не сообщалось, в какие именно фонды и на какие цели пойдут деньги, чтобы не повлиять на их выбор. Организаторы на свое усмотрение выбрали следующие: категория «мальчик» - на лечение конкретному мальчику фонду «Шанс»; «девочка» - на лечение конкретной девочке фонду «Шанс»; «бабушка» - «Патронажная служба в регионах» от «Имена»; «дедушка» - «Помощь бездомным» от «Имена»; «животное» - ООЗЖ «Эгида». 
Таким образом, ответы участников третьего эксперимента, которые не оставили деньги, должны быть ближе к ответам в первом и втором экспериментах, нежели ответы тех, кто отдал свои деньги на благотворительность.

Bторое: готовность респондентов отдать деньги на благотворительность обусловлена их личностными характеристиками.

Если рассматривать эти характеристики через критерии теста «Большой пятерки», то в связи с анонимностью опросов целесообразно предположить, что ключевыми факторами, влияющими на склонность людей к благотворительности, являются дружелюбие и добросовестность. Возможно также положительное влияние показателя «открытости к новому опыту», особенно для студентов, т. к. благотворительность может не являться обычной деятельностью для них. В таком случае желание отдать деньги на благотворительность они могут рассматривать как получение нового опыта и впечатлений. Не исключена и вероятность того, что само участие в эксперименте будет стимулом отдать деньги на благотворительность за счет новизны ощущений.

Tpeтье: предпочтения респондентом определенной группы получателей благотворительной помощи также будут обусловлены личностными характеристиками опрашиваемых.

Для проведения эксперимента было набрано 49 добровольцев, являющихся студентами 1 и 2 курса Белорусского государственного экономического университета (45 девушек и 4 юноши).

По результатам эксперимента, 26 человек (53,1\% всех респондентов) отдали собственные деньги в качестве благотворительной помощи. Предпочитаемые категории реципиентов представлены на графике (рис. 4), для сопоставления также приведены полученные ответы по второму эксперименту («Чужие деньги»).

Как видим, студенты, решившие отдать деньги на благотворительность, имеют большую процентную разницу в выборе той или иной группы, в отличие от респондентов, не отдавших свои деньги или отвечавших за распределение чужих денег.

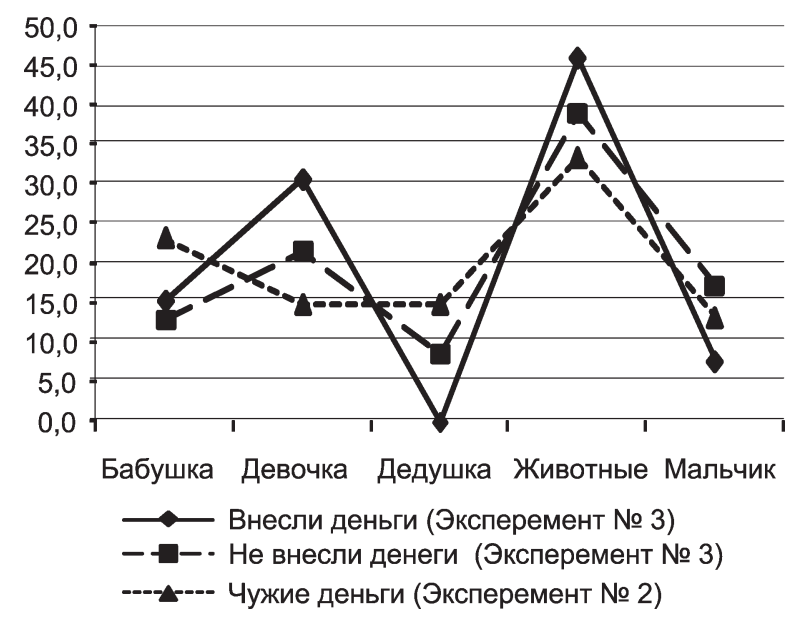

Рис. 4. Распределение пожертвований по категориям (результаты второго и третьего эксперимента), \%

Источник. Авторская разработка.

Расчет степени близости структуры ответов той или иной группы можно осуществить с помощью индекса Салаи и индекса Рябцева, результаты которых могут находиться в диапазоне [0; 1]. Чем существеннее отличаются структуры ответов, тем ближе индексы к 1. Результаты расчета представлены в табл. 1.

Как видно из таблицы, структуры ответов, согласно индексу Рябцева, имеют существенный уровень отличий, за исключением сопоставления ситуаций, где респонденты принимали решение оставить собственные деньги (Эксперимент № 3 Оставившие деньги) и использование гипотетической суммы (Эксперимент № 1), где наблюдается значительный уровень различия. Результаты индекса Салаи показывают наибольшую близость структур в ситуациях с гипотетической суммой, распределением чужих денег (Эксперимент № 2) и где респондент принял решение не отдавать собственные деньги на благотворительность (Эксперимент № 3 - Не оставившие деньги). При этом наиболее существенное отличие в ответах от всех других участников наблюдается у отвечающих в условиях эксперимента № 3, решивших оставить собственные деньги на благотворительность. Такое различие может быть обусловлено тем, что данные респонденты более осмысленно подходили к выбору и результаты их ответов больше соответствует их реаль- 
Индексы Салаи по структуре ответов для различных групп отвечающих

\begin{tabular}{|c|c|c|c|c|c|}
\hline \multirow{2}{*}{\multicolumn{2}{|c|}{ Группа отвечающих }} & \multirow{2}{*}{$\begin{array}{c}\text { Эксперимент } \\
\quad \text { № } 1\end{array}$} & \multirow{2}{*}{$\begin{array}{c}\text { Эксперимент } \\
\quad \text { № } 2\end{array}$} & \multicolumn{2}{|c|}{ Эксперимент № 3} \\
\hline & & & & $\begin{array}{c}\text { Оставившие } \\
\text { деньги }\end{array}$ & $\begin{array}{c}\text { Не оставившие } \\
\text { деньги }\end{array}$ \\
\hline \multicolumn{2}{|c|}{ Эксперимент № 1} & - & $0,24(0,26)$ & $0,54(0,37)$ & $0,25(0,28)$ \\
\hline \multicolumn{2}{|c|}{ Эксперимент № 2} & $0,24(0,26)$ & - & $0,5(0,26)$ & $0,2(0,16)$ \\
\hline \multirow[t]{2}{*}{$\begin{array}{l}\text { Эксперимент } \\
\text { № } 3\end{array}$} & $\begin{array}{c}\text { Оставившие } \\
\text { деньги }\end{array}$ & $0,54(0,37)$ & $0,5(0,26)$ & - & $0.49(0,16)$ \\
\hline & $\begin{array}{c}\text { Не оставившие } \\
\text { деньги }\end{array}$ & $0,25(0,28)$ & $0,2(0,16)$ & $0,49(0,16)$ & - \\
\hline
\end{tabular}

Примечание. В скобках представлены значения индекса Рябцева, вне скобок - индекса Салаи.

Источник. Авторская разработка.

ным предпочтениям. Таким образом, на основе статистических методов анализа мы находим подтверждение первому предположению.

Для проверки второй гипотезы о влиянии личностных характеристик на склонность к благотворительности была составлена логит-модель, где результирующий показатель принимает значение 1, если было принято решение передать деньги на благотворительность, и 0, если респондент оставил деньги себе. Модель была проверена на наличие мультиколлинеарности, гетероскедастичности и эндогенности. Результаты регрессионного анализа представлены в табл. 2.

Как видно из таблицы, наиболее значимыми личностными характеристиками, влияющими на готовность людей оставить деньги на благотворительность в ходе проводимого эксперимента, являются экстравертность и открытость новому опыту. При этом коэффициент при параметре «экстравертность» имеет отрицательный знак, что говорит о том, что при таких условиях рост данного показателя на единицу приводит к сокращению вероятности того, что люди отдадут деньги, на 13,5\%.

Указанное обстоятельство может быть обусловлено анонимностью проводимого опроса. Высокий уровень экстравертности предполагает высокую реакцию на внешние стимулы, в том числе на похвалу за социально поощряемую деятельность. Однако в условиях анонимности такие индивиды не могут рассчитывать на такое поощрение. Как следствие, и сама деятельность может для них стать менее привлекательной.

Полученное значение коэффициента при параметре открытости новому опыту является положительным, что соответствует выдвинутой ранее гипотезе. Согласно расчетам, рост данного показателя на еди-

Таблица 2

Результаты логит-модели влияния индивидуальных характеристик на склонность к благотворительности

\begin{tabular}{|c|c|c|}
\hline $\begin{array}{c}\text { Личностные } \\
\text { характеристики теста } \\
\text { «Большая пятерка» }\end{array}$ & $\begin{array}{l}\text { Отдадут } \\
\text { ли деньги }\end{array}$ & $\begin{array}{c}\text { Предельные } \\
\text { эффекты }\end{array}$ \\
\hline \multirow{2}{*}{ Экстравертность } & $-0,763$ & $-0,135$ \\
\hline & $(0,379)$ & \\
\hline \multirow{2}{*}{ Дружелюбие } & $-0,276$ & $-0,049$ \\
\hline & $(0,370)$ & \\
\hline \multirow{2}{*}{ Добросовестность } & 0,442 & 0,078 \\
\hline & $(0,463)$ & \\
\hline \multirow{2}{*}{$\begin{array}{l}\text { Эмоциональная } \\
\text { стабильность }\end{array}$} & 0,305 & 0,054 \\
\hline & $(0,328)$ & \\
\hline \multirow{2}{*}{$\begin{array}{l}\text { Открытость новому } \\
\text { опыту }\end{array}$} & $1,152 * *$ & 0,204 \\
\hline & $(0,368)$ & \\
\hline \multirow{2}{*}{ Константа } & $-3,838$ & $-0,679$ \\
\hline & $(2,886)$ & \\
\hline $\begin{array}{l}\text { Количество } \\
\text { наблюдений }\end{array}$ & 49 & \\
\hline $\begin{array}{l}\text { Логарифмическое } \\
\text { правдоподобие }\end{array}$ & $-25,994$ & \\
\hline Критерий Акаике & 63,987 & \\
\hline
\end{tabular}

Примечание. В скобках значение $t$-статистики: * - значим на уровне $5 \%$; * - значим на уровне $1 \%$.

Источник. Авторская разработка. 
ницу увеличивает вероятность осуществления пожертвований на 20,4\%. Такое влияние, как отмечалось ранее, может быть связано с тем, что для студентов сам акт благотворительности может рассматриваться как новый опыт. Для всех других параметров теста «Большой пятерки» взаимосвязь личных характеристик и склонности к благотворительности оказалась незначимой.

Как следствие, мы находим статистические подтверждения второй гипотезе о том, что личностные характеристики респондента частично оказывают влияние на желание отдать деньги на благотворительность.

В ходе анализа не было выявлено статистически значимого влияния личностных характеристик респондентов, пожертвовавших деньги, на выбор предпочитаемой ими группы реципиентов, а следовательно, третье предположение не нашло своего подтверждения.

Продолжение исследований и практическое использование результатов:

- проведенное исследование было сосредоточено на выявлении предпочтительных категорий субъектов для пожертвований, однако в этом случае возможно занижение выявленного уровня склонности к благотворительности - люди более склонны жертвовать одному конкретному лицу, чем группе людей, имеет место «угасание сострадания» (Cameron, Payne, 2011; Västfjäll, Slovic, Mayorga, Peters, 2014). Одним из возможных решений данной проблемы является формирование «идентичности благотворителя», т. е. люди, имеющие или приобретающие определенные убеждения и образ себя, склонны жертвовать больше времени и денег (Bryan, Master, Walton, 2014; Koo, Fishbach, 2016; Markowitz, Slovic, Västfjäll, Hodges, 2013).

На практике благотворительные организации прибегают к рекламе своих кампаний, стимулирующих «эмоциональную благотворительность», где ставка делается не на статистические данные, а на показ реального индивидуального субъекта. Эксперименты подтверждают эффективность такого подхода ${ }^{18}$ (Small, Loewenstein, 2003;

18 Более того, люди, подверженные «эмоциональной благотворительности», снижают свои пожертвования, если им предоставляется дополнительная информация об эффективности кампании. Авторы выдвинули гипотезу, что эффект «теплого свечения» работает в случае эмоциональ-
Lee, Feeley, 2016). Следует отметить, что реклама «эмоциональной благотворительности», как правило, используется для сбора денег для помощи детям и животным, которые, согласно результатам нашего исследования, и так являются приоритетными субъектами для пожертвований. Необходимо усилить рекламные кампании по сбору помощи для пожилых людей;

- исследование пыталось выявить индивидуальные характеристики благотворительного поведения, тогда как социальное давление и «заразная щедрость» могут значительно увеличить размер пожертвований (Fowler, Christakis, 2010);

- за пределами исследования остался выбор между пожертвованиями деньгами и временем, т. е. волонтерством. Ряд исследований показывает, что волонтерство может приводить к более значительному эффекту как с точки зрения успеха благотворительной кампании ${ }^{19}$, так и уровня удовлетворенности самого донора (Brown, Meer, Forest, 2019; Lalin, Aknin, Norton, Dunn, 2009). Интересный кейс для организации благотворительных мероприятий представляет выявленный в ряде исследований «эффект мученичества», где чем больше боли или усилий нужно приложить, тем больше склонность к благотворительности ${ }^{20}$ (Olivola, Shafir, 2013);

- интерес и практическую значимость представляет исследование динамики повторяющихся пожертвований - как они меняются со временем, какие факторы способны на них повлиять. Некоторые исследователи говорят о формировании привычки к пожертвованиям как об установлении долгосрочной нормы щедрого поведения, в то же время экспериментальные данные не подтверждают существование тренда к со-

\footnotetext{
ных стимулов, тогда как «рациональные» благотворители положительно реагируют на дополнительные данные о ходе благотворительной кампании (Karlan, Wood, 2017).

19 Интересным результатом исследования оказалось то, что люди склонны заниматься волонтерством даже если это невыгодно с точки зрения денежной оценки затраченного времени (потерянные заработки превышали размер предложенного денежного пожертвования в качестве альтернативы).

${ }^{20} \mathrm{C}$ этой точки зрения более эффективно организовывать благотворительные марафоны, субботники, уборки парков, чем пикники.
} 
хранению устойчивой склонности к пожертвованиям ${ }^{21}$ (Leliveld, Risselada, 2017);

- в экспериментах со студентами сумма пожертвований была взята из результатов первого эксперимента, где принимали участие работники международной фирмы, при этом для различных групп респондентов допустимая медианная сумма благотворительности могла отличаться. Определение данной суммы может выступать предметом последующих исследований;

- выявленное влияние личностных характеристик на склонность к благотворительности не позволяет определить, какие черты личности оказывают наибольшее влияние непосредственно на сумму пожертвований, сохранится ли данная склонность у тех, кто сделал пожертвования при других условиях эксперимента (например, при отсутствии анонимности). Такого рода исследования в дальнейшем позволят формировать более эффективные кампании по сбору пожертвований;

- на основе накопленного опыта и экспериментальных исследований формируется ряд «поведенческих подталкиваний», рекомендаций для благотворительных организаций по повышению эффективности работы. Например, Behavioural Insights Team (BIT), один из наиболее авторитетных центров поведенческой экономики, предлагает следующие принципы (Sanders, 2013): «сделать это легко» (упрощение, автоматическая подписка, вариант по умолчанию); «привлечь внимание» (персонализированное сообщение, награда за поведение ${ }^{22}$, поощрение взаимности маленькими подарками ${ }^{23}$; « «осредоточиться на социальном эффекте» (задействовать выдающихся личностей, публичность ${ }^{24}$, установление групповых норм $^{25}$ ); «время имеет значение».

Таким образом, в серии экспериментов было выявлено, что предупреждение потенциальных доноров увеличивает меди-

21 Более того, единожды пожертвовав деньги, ряд участников эксперимента оставляли в следующих раундах экспериментов заработанные от прохождения опросов деньги себе в качестве моральной компенсации за сделанное хорошее дело.

22 Налоговые вычеты в развитых странах давно используются для стимулирования благотворительного поведения юридических и физических лиц. Подобные вычеты с 2004 г. практикуются, например, в Польше - вы можете выбрать, какой благотворительной организации из анную сумму пожертвований, однако также ведет к росту отказов от участия и избегание встречи с волонтером. Облегчение данного избегания для респондентов, с одной стороны, может снизить издержки для благотворительной организации (работники будут обходить только согласных принять участие), но одновременно с этим снизит и общую сумму пожертвований, т. к. будут исключаться люди, на которых сильное воздействие оказывает эффект социального давления.

При выборе дизайна благотворительных мероприятий целесообразно ориентироваться на ключевые личностные характеристики потенциальных доноров. Так, анонимная благотворительность скорее всего не найдет отклик у людей с высоким уровнем экстравертности, а акцент в рамках кампании на новизну опыта может, при прочих равных условиях, привлечь больше участников.

списка вы отдадите сумму не менее 1\% подоходного налога (подробнее URL: https://www.ekonomiaspoleczna.gov.pl/ How,to,donate,1,559.html). Суммы пожертвований растут: в 2019 г. поляки передали неправительственным организациям 8199 млн евро, что на 25,3 млн евро больше, чем в предыдущем году.

${ }_{23}$ В исследовании А. Фалька в письма (с просьбой о пожертвовании школе в Бангладеш) вкладывались открытки с рисунками детей. Добавление одной открытки увеличило количество пожертвовавших на 17\%; добавление 4 открыток - на 75\% (Falk, 2007). В Великобритании банкирам предлагали пожертвовать свой дневной заработок (в среднем 515 ф.ст.), стимулируя их разными способами: визит знаменитости, коробка сладостей, персонализированное письмо, сладости и письмо. Последний метод увеличил количество пожертвовавших с 5 до $17 \%$ (Sanders, 2015).

${ }^{24}$ В исследовании Д. Ариэли и др. публичность увеличивала величину пожертвований для «Красного креста», но не для «Оружейного союза США», которому предпочитали жертвовать анонимно. Публичность выступала внутренним мотивом (репутационная мотивация), которая может вытесняться внешней мотивацией (оплатой). Деньги как стимул стоит применять осторожно: они приводили в данном эксперименте к снижению пожертвований «Красному кресту», если об этом было сообщено публично (Ariely, Bracha, Meier, 2009). Аналогичный эффект оказывают денежные стимулы на многих доноров крови, которые теряют внутреннюю мотивацию для своей деятельности (CostaFont, Jofre-Bonet, Yen, 2011).

${ }^{25}$ В формировании норм помогает «эффекта якоря». Например, люди увеличивали свои пожертвования на сайтах благотворительных организаций, если им выдавалась информация о большем размере пожертвования предыдущего донора (Smith, Windmeijer, Wright, 2015). Если установить несколько прозрачных боксов для пожертвований с разным содержимым (мелкие купюры, монеты, большие купюры), то люди будут склонны делать похожие пожертвования, чтобы соответствовать тому, что есть в боксе (Martin, Randal, 2008). 
Выявление предпочитаемых категорий реципиентов благотворительной помощи целесообразно проводить, используя реальные денежные средства самих опрашиваемых, что снижает вероятность случайных и ложных ответов респондентов.

\section{СПИСОК ЛИТЕРАТУРЫ (REFERENCES)}

Егорова М.С., Паршикова О.В. 2016. Психометрические характеристики Короткого портретного опросника Большой пятерки (Б5-10). Психологические исследования. No 9. URL: http:// psystudy.ru [Egorova M.S., Parshikova O.V. 2016. Psychometric characteristics of the Short Portrait Questionnaire of the Big Five (B5-10). Psikhologicheskie issledovaniya. No 9. URL: http://psystudy.ru (In Russ.)]

Ariely D., Bracha A., Meier S. 2009. Doing Good or Doing Well? Image Motivation and Monetary Incentives in Behaving Prosocially. American economic review. Vol. 99. No 1. PP. 544-555.

Brown A., MeerJ., Forest W. 2019. Why Do People Volunteer? An Experimental Analysis of Preferences for Time Donations. Management Science. Vol. 65. No 4. PP. 1455-1947.

Bryan C. J., Master A, Walton G.M. 2014. «Helping» versus «being a helper»: invoking the self to increase helping in young children. Child development. No 85. PP. 1836-1842.

Cameron C.D., Payne B.K. 2011. Escaping affect: how motivated emotion regulation creates insensitivity to mass suffering. Journal of personality and social psychology. No100. PP. 1-15.

Costa-Font J., Jofre-Bonet M., Yen S. 2011. Not All Incentives Wash Out the Warm Glow: The Case of Blood Donation Revisited. CESifo Working Paper. No 3527.

Deaton A. 2013. The Great Escape: Health, Wealth, and the Origins of Inequality Hard. Princeton University Press. Princeton. PP. 596-617.

DellaVigna S., List J., Malmendier U. 2012. Testing for Altruism and Social Pressure in Charitable Giving. The Quarterly Journal of Economics. Vol. 27. PP. 1-56.

Duflo E., Kremer M., Robinson J. 2011. Nudging Farmers to Use Fertilizer: Theory and Experimental Evidence from Kenya. American Economic Review. Vol. 101. No 6. PP. 2350-2390.

Falk A. 2007. Gift Exchange in the Field. Econometrica. Vol. 75. Iss. 5. PP. 1501-1511.

Fowler J., Christakis N. 2010. Cooperative behavior cascades in human social networks. PNAS. No 107. PP. 5334-5338.
Horowitz J. 2006. «The Use of a Real-Money Experiment in a Stated-Preference Survey». Using Experimental Methods in Environmental and Resource Economics. Chapter 4. Edward Elgar Publishing.

Karlan D., Wood D. 2017. The effect of effectiveness: Donor response to aid effectiveness in a direct mail fundraising experiment. Journal of Behavioral and Experimental Economics (formerly The Journal of Socio-Economics), Elsevier. Vol. 66(C). PP. 1-8.

Koo M., Fishbach A. 2016. Social Psychological and Personality Science Giving the Self: Increasing Commitment and Generosity Through Giving Something That Represents One's Essence. Sage Journals. Vol. 7 No 4. PP. 339-348. URL: https://doi.org/10.1177/1948550616628607

Lalin A., Aknin L.B., Norton M.I., Dunn E.W. 2009. Feeling Good about Giving: The Benefits (and Costs) of Self-Interested Charitable Behavior. Harvard Business School Marketing Unit Working Paper. No 10-012. URL: https://papers.ssrn.com/ sol3/papers.cfm?abstract_id=1444831

Lee S., Feeley T. 2016 . The identifiable victim effect: a meta-analytic review. Social Influence. Vol. 11. No 3. PP. 199-215.

Leliveld M., Risselada H. 2017. Dynamics in charity donation decisions: Insights from a large longitudinal data set. Science advances. No 3(9): e1700077.

Locey M.L., Jones B.A., Rachlin H. 2011. Real and hypothetical rewards. Judgm Decis Mak. No 6. PP. 552-564.

Markowitz M., Slovic P., Västfjäll D., Hodges S. 2013. Compassion fade and the challenge of environmental conservation. Judgment and Decision Making. Vol. 8. No 4. PP. 397-406.

Martin R., Randal J. 2008. How is donation behavior affected by the donations of others? Journal of Economic Behavior E Organization. Vol. 67. Iss. 1. PP. 228-238.

Olivola C., Shafir E. 2013. The Martyrdom Effect: When Pain and Effort Increase Prosocial Contributions. Journal of Behavioral Decision Making. No 26. PP. 91-105.

Sanders M. 2013. Applying behavioural insights to charitable giving. Cabinet Office and Behavioural Insights Team. URL: https://www.bi.team/ wp-content/uploads/2015/07/BIT_Charitable_ Giving_Paper-1.pdf

Sanders M. 2015. In search of the limits of applying reciprocity in the field: Evidence from two large field experiments. URL: http://38r8om2 xjhhl25mw24492dir-wpengine.netdna-ssl.com/wpcontent/uploads/2015/08/In-search-of-the-limits-ofapplying-reciprocity-in-the-field.pdf 
Small D.A., Loewenstein G. 2003. Helping a Victim or Helping the Victim: Altruism and Identifiability. Journal of Risk and Uncertainty. No 26. PP. 5-16.

Smith S., Windmeijer F., Wright E. 2015. Peer Effects in Charitable Giving: Evidence from the (Running) Field. The Economic Journal. No 125. PP. 1053-1071.

Västfjäll D., Slovic P., Mayorga M., Peters E. 2014. Compassion Fade: Affect and Charity Are Greatest for a Single Child in Need. PLoS ONE. No 9(6): e100115.

In citation: Belorusskiy Economicheskiy zhurnal. 2020. No 3. PP. 74-86.

Belarusian Economic Journal. 2020. No 3. PP. 74-86.

\title{
EXPERIMENTAL APPROACHES TO IDENTIFICATION INCENTIVES FOR CHARITY BEHAVIOUR
}

\author{
Elina Babicheva ${ }^{1}$, Tatiana Maibarada ${ }^{1}$, Aliaksandr Krauchanka ${ }^{1}$ \\ Authors affiliation: ${ }^{1}$ Belarusian State Economic University (Minsk, Belarus). \\ Corresponding author: Tatiana Maibarada (mtv_1@tut.by).
}

ABSTRACT. The article touches upon the experimental approaches to identify people's propensity for charity and detect the groups of the recipients definitely preferred over the others. The results of three economic experiments are compared that enables to analyse how the features of experimental design affect respondents' preferences, for instance, while using hypothetical amounts of donations and their own money. The experiments revealed the effect of informing potential donors about the upcoming fundraising both on the amount of donations and on the number of refusals to participate. The authors further investigate the relationship between respondents' personal characteristics and their willingness to be involved in charity anonymously. Correlation was found between the propensity for anonymous charity and the characteristics of extraversion, openness to new experience. The article gives some practical proposals for organizing behavioral interventions when setting up charity events and defines potential directions for further experimental research on charitable activities.

KEYWORDS: experimental economics, behavioral economics, charity, experimental design.

JEL-code: B41, C81, C90, C91, D03, D64.

DOI: $10.46782 / 1818-4510-2020-3-74-86$

Received 5.05.2020 